\title{
Una aproximación a las geografías imaginarias en la obra de Ignacio Minaverry
}

ABSTRACT: Based on Edward Soja's (2010) concepts of imaginary geographies and third space an analysis is outlined of the make-up of Ignacio Minaverry's works «20874», «Rat-line», and «Next year in Bobigny», both from spatial and gendered perspectives. Three «spatial stories» may be identified: the one constructed within the space of the page; another reconstructed from both the real and the imaginary journeys through the cities of Berlin, Bobigny, and Vivar; and lastly, the one constructed through the body and identities.

Keywords: Comics, Imaginary Geographies, Third Space, Feminist Geography, Ignacio Minaverry.

RESUMEN: A partir de los conceptos de Edward Soja (2010) de geografias imaginarias y tercer espacio se analiza la puesta en página de la obra de Ignacio Minaverry «20874», «Rat-line» $\mathrm{y}$ «El año próximo en Bobigny» a partir de una aproximación a la perspectiva espacial y desde un enfoque de género. Se identifican tres «relatos» espaciales: el construido desde el espacio de la hoja; el que reconstruye los recorridos reales e imaginarios en tres ciudades: Berlín, Bobigny y Vivar; y el de la construcción del cuerpo y las identidades.

Palabras clave: historietas, geografías imaginarias, tercer espacio, geografía feminista, Ignacio Minaverry. 


\section{Introducción}

Este ensayo explora las geografías imaginarias en la puesta en página de las historietas «20874», «Rat-line» y «El año próximo en Bovigny» de Ignacio Minaverry publicadas en Fierro entre 2007 y 2011 a partir de una aproximación a la perspectiva espacial y desde un enfoque de género.

Parto de una interpretación teórica que combina las propuestas que trabajan la relevancia del espacio en la constitución de la sociedad con aquellas que discuten la relación entre espacio y género para identificar tres relatos espaciales que conviven en la historieta: aquel construido desde el propio formato -el espacio de la hoja- que pone en diálogo imagen y texto; aquel que reconstruye los recorridos reales e imaginarios de la heroína en el espacio y en el tiempo, y que se articulan entre tres ciudades reales/imaginarias: Berlín, Bobigny y Vivar y que destacan el carácter heterotópico de esa geografía; y aquel último que asocia el espacio a la construcción del cuerpo y la identidad femenina.

Esta aproximación es deudora del desarrollo de Edward Soja (2010) quien sostiene que el cruce de las ciencias sociales y de la geografía con el postestructuralismo ha propiciado un «giro espacial» en las primeras y un «giro cultural» en la segunda que lo lleva a postular una «imaginación geográfica» como dimensión insoslayable a la par de la imaginación histórica y la imaginación social. Lo dicho, que explica un encuentro relativamente reciente, llama a una reflexión de cómo - a pesar del esfuerzo con el que geógrafas/os insisten en que todo fenómeno social debe ser considerado en su aspecto sociohistóricoespacial- el espacio suele ser una dimensión poco problematizada que, según Soja, precisa ser analizada por sus implicancias subjetivas. Expresa el autor (2010: 185):

Estudiar la historicalidad de un acontecimiento, persona, lugar o grupo social, no ofrece necesariamente una mejor aproximación que estudiar su socialidad y su espacialidad. Los tres términos y las complejas relaciones entre ellos deben estudiarse conjuntamente como fuentes de conocimiento fundamentales y entrelazadas, ya que «ser-en-el-mundo» consiste precisamente de ello. La combinación de las perspectivas histórica, social y espacial da mejor cuenta teórica y práctica del mundo.

Esta es también la aproximación que propone la geógrafa feminista Doreen Massey para quien «[...] los espacios y los lugares, así como el sentido que tenemos de ellos -junto con otros factores asociados, como nuestros grados de movilidad- se estructuran sobre la base del género [...] [lo que] refleja las maneras cómo el género se construye y entiende en nuestras sociedades, y tiene efectos sobre ellas» (1998: 40). 
Podemos decir que, a grandes rasgos y salvando los matices que cada autor pueda introducir, el lugar puede ser entendido como un área limitada, como una porción concreta del espacio con una gran carga simbólica y afectiva. Los lugares dan carácter al espacio y encarnan las experiencias y las aspiraciones de los individuos, ya sea individual o colectivamente. El espacio, en cambio, tendría un carácter más abstracto e indiferenciado, que se convierte en lugar a medida que le vamos otorgando significados y valores. Espacio y lugar son, por tanto, dos formas entre las que existe una tensión dialéctica parecida a la que puede existir entre individuo y comunidad, entre lo público y lo privado, entre lo masculino y lo femenino (Nogué i Font, 1989: 69).

Por otra parte, Gillian Rose (1999) considera el espacio como el resultado de la relación entre discursos, fantasías y corporalidad situados entre el yo y la otredad. Este espacio es pensado -siguiendo el desarrollo que Judith Butler hace del género- como performativo. Es decir que, en ambos casos, el género y el espacio están realizándose pero no pre-existen al acto mismo del sujeto que se constituye en el acto. Tanto el género como el espacio son dinámicos y la aparente estabilidad es resultado de la iteración, la práctica consuetudinaria que conforma a los cuerpos sexualizados como varones-masculinos-heterosexuales o mujeresfemeninas-heterosexuales (coherencia que produce la matriz heterosexual) y a los espacios como escenarios estables donde suceden los hechos. Pero además establece otra relación entre género y espacio, una que ya Butler señala y Rose subraya: el afuera constitutivo del sujeto dominante está conformado por esas zonas inhabitables densamente pobladas por los cuerpos abyectos, aquellos que no adquieren el status que exige la matriz de heterosexualización binaria. Lo que queda por fuera marca el límite del sujeto dominante y reafirma su identidad. De forma que, género y espacio se co-construyen operando uno en otro.

Por su parte, Michel Foucault ha teorizado sobre espacio y construcción de subjetividad en sus escritos sobre heterotopías como contra-espacios o utopías situadas. «Utopías y heterotopías» y «El cuerpo utópico», ${ }^{1}$ son textos germinales de lo que luego Foucault desarrollará en «De los espacios otros» (1967). A diferencia de los espacios disciplinarios, destinados a producir cuerpos dóciles y productivos, encontramos en estos textos una teorización sobre los espacios de resistencia como esos «lugares que se oponen a todos los demás y que de alguna manera están destinados a borrarlos, compensarlos, neutralizarlos o purificarlos». Son lugares reales fuera de todo lugar, en este sentido, algunos espacios representados en la

1. Ambos textos son las transcripciones respectivas de dos conferencias radiofónicas pronunciadas por Michel Foucault el 7 y el 21 de diciembre de 1966 en France-Culture, en el marco de una serie de emisiones dedicadas a la relación entre utopía y literatura. La traducción es de Rodrigo García para la revista mexicana Fractal. 
historieta de Minaverry, como la Cité de Bobigny o la unidad habitacional Le Corbusier Haus (Berlín) constituyen heterotopías. En este punto, sin embargo, es necesario señalar que aunque el concepto de Foucault refiere a espacios o contraespacios situados, en los que subraya su real emplazamiento, tal como propone Marta Sierra (2010) hacemos extensivo el concepto para el análisis de estos contraespacios en representaciones pictóricas, literarias y nuestro caso, historietísticas. Como sostiene Sierra en su análisis sobre la obra pictórica de Norah Borges: «Aunque las heterotopías sean "sitios verdaderos" estos se encuentran dotados con una calidad imaginaria o virtual que los localiza fuera de todos los sitios». La autora sostiene así que su interés por las heterotopías obedece al carácter reflexivo de estas, ya que estos contraespacios representados actuarían como espejos que transforman su referente por inversión, mientras crean otros espacios que compensan posiciones sociales insatisfactorias.

\section{La historia de Dora Bardavid, la joven caza-nazis}

Dora. Número 1. 1959-1961 (Minaverry, 2009) reúne las dos primeras historias que relatan la experiencia de una joven que a fines de los años 50 se convierte en espía caza-nazis. En la primera historia, Dora descubre el nombre de su padre -Iakó Bordavid- junto al número que lo registra en el campo de concentración: «20874». La búsqueda del paradero de nazis fugados se vuelve central en la siguiente historia: «Rat line» en la que la política europea y la historia nacional se cruzarán en Vivar, un pueblito de la provincia de Buenos Aires al que Dora llega con sus investigaciones a partir de un dato de su amiga Judith que trabaja para el arqueólogo filonazi Otto Graf. En la siguiente tira, ya de regreso a Francia, Dora es contactada por la abogada Beatrice Roubini para proseguir con sus pistas, mientras comienza una relación con Geneviève Junot (una joven gitana que busca datos de su familia, de la que fue separada de bebé por el régimen nazi) y ayuda a su amiga Odile a conseguir el dinero para interrumpir un embarazo no deseado.

En primer lugar, presento una indagación sobre la construcción narrativa secuencial en el espacio de la hoja. Exploraré luego la representación sociohistórica y espacial que se presenta de Berlín, Bobigny y Vivar en la que actúan los personajes de la historieta. En tercer lugar, abordaré la representación de la sexualidad y el cuerpo como topos y su relevancia en la tira analizada. 


\section{Puesta en página: narración secuencial en el espacio de la hoja en blanco}

La imbricación de lo icónico y lo verbal sobre el plano en un relato secuencial constituye lo específico de las historietas. Como señala Federico Reggiani (2008: 5):

La historieta es un tipo de lenguaje que puede leerse a partir de analogías con otros, en particular con la literatura, con quien comparte un marco institucional (la industria editorial), soportes (la revista, el libro) y una práctica (la lectura); y con el cine, con quien comparte su carácter híbrido (la combinación de imágenes y palabras) y un principio de construcción, el montaje. [...] Pero más allá de estas similitudes -que habría que problematizar- hay un elemento que vuelve a la historieta un lenguaje peculiar, $[\ldots]$ el modo en que ocupa un espacio (típicamente, la página rectangular de una revista o un libro) disponiendo de ciertas unidades básicas en que organiza la materia narrativa, las viñetas.

$\mathrm{Al}$ aproximarnos al análisis de una historieta, por lo tanto, además del análisis de la historia, con sus personajes y conflictos, que pertenecen al plano de lo enunciado, debemos tener en cuenta la instancia de comunicación denominada enunciación. ${ }^{2}$ En el plano de la enunciación, la puesta en página -instancia de organización y disposición espacial de lo que se quiere narrar- plasma elecciones que, como el montaje en el cine, resultarán relevantes para la construcción del relato. Así, por ejemplo, la disposición de las viñetas, su tamaño y variación a lo largo del relato, la relación siempre conflictiva entre palabra e imagen, el uso del color, el encuadre elegido subrayan lo que puede entenderse como característico del mecanismo enunciativo en las historietas: la exhibición constante de su carácter de construcción. La historieta, a diferencia de otros lenguajes como el fílmico, no minimiza su instancia de enunciación, no puede hacerlo, porque «la posibilidad de borrar el significante está en historieta bloqueada por la necesaria exhibición de la cadena narrativa sobre el plano de la página» (Reggiani, 2008: 6).

Minaverry utiliza el espacio de la página de manera bastante libre. En la puesta en página podemos observar la disposición espacial de las viñetas y las diferencias de tamaño que ponen en tensión el hipercuadro -que conforma la página en su conjunto- con la unidad de la viñeta. Aunque las viñetas conforman

2. Oscar Steimberg (2005) define como 'enunciación' el efecto de sentido de los procesos de semiotización por los que en un texto se construye una situación comunicacional, a través de dispositivos que podrán ser o no de carácter lingüístico. La definición de esa situación puede incluir la de la relación entre un 'emisor' y un 'receptor' implícitos, no necesariamente personalizables. 
una unidad están en relación de solidaridad no solo con la secuencia lineal de lectura sino con el cuadro general de la página [ver figura 1 en anexo].

El análisis del lenguaje historietístico precisa la atención de la conjunción de dos regímenes de representación en el plano: la palabra y la imagen. Dos cuestiones interesa destacar: por un lado, la discusión de si la imagen es más importante que la palabra. Por otro, el hecho de que la inclusión de la palabra, cuando existe, es representación gráfica.

En el primer caso estamos ante la definición misma de la historieta. La aceptación de que la imagen es la dominante, como ha señalado Thierry Groensteen (citado en Reggiani, 2009) se enfrenta al carácter discursivo de cualquier representación. En otras palabras, podemos decir que la producción de imágenes desde el esbozo de la idea y la construcción del guion -aunque la historieta sea «muda»- está habitada por palabras. Por lo que, puede decirse que la conjunción de estos dos regímenes de representación no se sintetizan, sino que devienen en ese tercer espacio híbrido, contradictorio que le permite afirmar a Federico Reggiani que toda historieta construye un «discurso irónico». (Reggiani, 2010: 5).

Esta posibilidad de registro que tiene la historieta constituye la tensión entre lo que se dice y lo que se muestra [ver figura 2 en anexo]. Y nos lleva al segundo punto: la representación gráfica de la palabra. La palabra en la historieta no es un mero recurso. La palabra escrita es dibujo y esto puede apreciarse en las características distintivas que adquiere la palabra delegada en el discurso en las distintas protagonistas. Sobre el uso del color, aunque la mayor parte de la historieta de Minaverry es en blanco y negro, en algunas secuencias el color refuerza el dramatismo de las escenas, mientras que en otras obedece a la necesidad de la trama.

\section{Geografías imaginarias: heterotopías en viñetas}

Los espacios pueden ser reales e imaginados. Los espacios pueden contar relatos y desvelar historias. Los espacios pueden ser interrumpidos, apropiados y transformados a través de la práctica artística y literaria. Como dice Pratibha Parmar, «el uso y la apropiación del espacio son actos políticos».

EDWARD SOJA, El tercer Espacio

Antes de explorar las tres ciudades que recrea Minaverry en la historia de Dora, es preciso señalar que el autor tiene una -podríamos llamar-afición por la arquitectura y el diseño que vienen de familia. Hijo de un diseñador gráfico, desechó la idea de optar por la arquitectura por su desinterés en las matemáticas, 
según expresa en una entrevista periodística. ${ }^{3}$ Pero el dato no es menor si observamos el detalle con el que el autor se esmera en la recreación urbana y las reseñas de época. Otra referencia al respecto es el proyecto que integra Minaverry, $L a$ teja, sitio que recaba información sobre «los barrios obreros construidos por el Estado, por cooperativas o privados, con fotos y planos de los barrios, y el relato de la historia de las políticas de vivienda de la ciudad de Buenos Aires». ${ }^{4}$

El proyecto de La teja, de alguna forma ilumina algunos de los intereses que reaparecen en las historietas del autor. Por ejemplo, en «Rat Line» a través de la invención de Vivar, un pueblito de la provincia de Buenos Aires que el autor crea a partir de diferentes localidades del sur de esa provincia que exploró para tal fin. En «El año próximo en Bobigny» las políticas de vivienda serán uno de los tópicos abordados por el autor a partir de la puesta en página de las bidonvilles (asentamientos precarios) y las HLM (Habitation à Loyer Modéré o vivienda de alquiler moderado) que constituyeron inmensos barrios obreros inspirados en las «ciudades jardín» proyectadas como una solución al problema habitacional de la clase trabajadora en la Francia de los años sesenta.

En la primera historia que transcurre en Berlín durante los años posteriores a la guerra, Minaverry recrea algunos pocos espacios en los que se mueven Lotte y Dora. Estos son principalmente, el departamento -la Haus de Berlín de Le Corbusier- y el archivo, en tanto espacios cerrados, y espacios abiertos como la Catedral, el zoo y la estación de trenes.

Podemos señalar al menos dos heterotopías que aparecen retratadas en la obra de Minaverry. La primera es la Haus de Le Corbusier. La unidad de Berlín es recreada en «20874» y las Cités de L'Abreuvoir y L'Etoile -barrios obrerosen «El año próximo en Bobigny». La Haus pertenece a las Unités d'habitation que constituyen unas de las más famosas obras de Le Corbusier. En 1922 Le Corbusier presentó un radical plan urbano: la Ville Contemporaine, que era una crítica a la ciudad europea de ese entonces: ${ }^{5}$ hacinada, insalubre, sombría. Le Corbusier planteaba demoler todo y construir grandes bloques habitacionales rodeados de parques y dispuestos de manera que no se hicieran sombra entre sí.

3. «Atrápame si puedes» por Martín Pérez en Suplemento RADAR de Página 12 del 07 de febrero de 2010. Hay versión electrónica en http://www.pagina12.com.ar/diario/suplementos/ radar/26-5916-2010-02-07.html consultado el 20 de abril 2011.

4. Puede consultarse en http://lateja.wordpress.com/ consultado el 20 de abril 2011.

5. Se llegaron a construir cinco unidades habitacionales que constituirían la ciudad contemporánea: la más famosa de las unidades es la de Marsella, en Francia, llamada la Cité Radieuse o Ciudad Radiante (1945). Las otras son Nantes-Rezé (1952), Berlín (1956), Briey-en-Forêt (1957) y Firminy (1960). Fuente: http://moleskinearquitectonico.blogspot. com/2010/04/le-corbusier-unite-dhabitation-de.html consultado 20 de abril 2011. 
La ejecución de la unité berlinesa se efectuó entre 1956-59, cuando la ciudad aún no estaba dividida por el muro. ${ }^{6}$

La Unité de Berlín fue creada como un conjunto habitacional económico destinado a familias de escasos recursos. El concepto era hacer de estas grandes unidades pequeños pueblos independientes, cada uno con muchas viviendas de distintos tipos, desde departamentos individuales hasta residencias para familias de 10 personas. Incluiría servicios públicos que permitirían que las unidades funcionaran autónomamente: tiendas, áreas de deporte, equipamientos médicos y educativos dentro del propio edificio. Sin embargo, luego de un tiempo las unités empezaron a deteriorarse y no funcionaron como pequeñas ciudades independientes, como había imaginado Le Corbusier. Por su estructura algunos medios compararon las unidades de viviendas con un panal de abejas.

La segunda heterotopía como contraespacio puesta en página por el autor son las cités en cordones industriales, también llamadas banlieue HLM, que constituyeron una política pública estatal para resolver la precarización de las poblaciones de menos recursos, en muchos casos de las colonias, que habitaban en asentamientos precarios denominados bidonvilles [ver figuras 3 y 4 en anexo]

En las décadas del cincuenta y sesenta llegaron a Francia, como mano de obra barata, oleadas de inmigrantes de las colonias francesas y de otros países europeos. Debido a la falta de viviendas, muchos de estos inmigrantes tuvieron que construir barrios de emergencia en los que habitaban principalmente argelinos. La política de los gobiernos franceses fue represiva y llegó a haber una brigada especial de la policía que se ocupaba de evitar que los habitantes de las bidonvilles hicieran arreglos y modificaciones a sus casillas, cosa que estaba prohibida. En 1985 se terminaron de erradicar las bidonvilles y ciudades de tránsito en Francia.

La ciudad como espacio de constitución de la clase obrera es subrayada en la obra de Minaverry, algo que José Luis Oyón Bañales (2002) ha expresado críticamente sobre las aproximaciones de la historiografía:

[...] la ciudad sigue siendo, salvo excepciones, un simple telón de fondo, un mero escenario del proceso de formación de la clase, de sus comportamientos colectivos y de sus luchas políticas. La relevancia que la ciudad, y más en concreto la gran ciudad, ha tenido como caldo de cultivo de la formación del mundo obrero contemporáneo ha solido minimizar el papel del propio espacio urbano como un protagonista más de la historia de las clases populares.

6. El Muro de Berlín fue parte de las fronteras interalemanas y separó a la República Federal Alemana de la República Democrática Alemana desde el 13 de agosto de 1961 hasta el 9 de noviembre de 1989. 
En «El año próximo en Bobigny», el barrio de monoblocs en el que habita la pequeña banda no es un mero escenario, sino el espacio seguro contra un exterior percibido como amenazante. Una conversación entre Odile y Dora ilustra la interiorización de la mirada y el discurso dominante en la apreciación de las diferencias étnico-culturales y de clase; Odile le dice a Dora: «Nosotros somos todos hermanos, Dora. ¿Sabés lo difícil que es salir del barrio...? Afuera te miran distinto, desconfían, no te perdonan una...» y continúa: «Vos sos linda, te pueden confundir con una francesa. Pero a mí, a Larbi, a Medhí, siempre nos van a mirar mal». («El año próximo...», Fierro, 54, p. 65). La referencia a sus rasgos inconfundiblemente orientales, y su pertenencia al barrio obrero, limitan su movilidad. Dora, en cambio, es según la apreciación de Odile, más occidental, asociando esto a la belleza. Odile, la más combativa de las chicas Minaverry, reproduce el discurso que inferioriza a los descendientes de las colonias. La colonización también se produce en las subjetividades.

La movilidad de la que goza Dora, es puesta en página en la última historia por la presencia de mapas que señalan las trayectorias de la protagonista: de Amsterdam a Rabat y luego a Fez, de allí a París, de París a Berlín, luego a Bobigny, de allí a Vivar y de regreso a Bobigny. El último espacio recreado por Minaverry, el pequeño pueblito de la provincia de Buenos Aires, Vivar, es una invención del autor. Tal como en Berlín o en Bobigny, Minaverry busca que el espacio representado dé cuenta de las tensiones políticas por las que está atravesado y constituido.

\section{Cuerpo, espacio y representación}

Mi cuerpo es lo contrario de una utopía: es aquello que nunca acontece bajo otro cielo. Es el lugar absoluto, el pequeño fragmento de espacio con el cual me hago, estrictamente, cuerpo. Mi cuerpo, implacable topía.

Michel FoucAult, El cuerpo utópico

Ignacio Minaverry había comenzado el relato de Dora por la historia de una espía que llegaba a la Argentina tras la pista de un filonazi, el antropólogo Otto Graff, que resultó ser la segunda historia que se publica en Fierro, «Ratline». La historia del archivo de Berlín, «20874», fue escrita con posterioridad como comienzo del relato y coincide con la inquietud de Minaverry de situar las motivaciones personales de Dora en el periodo de desnazificación, para visibilizar las tareas de las nuevas generaciones frente al horror heredado. La estrecha relación entre el espacio, la historia y la subjetividad se sintetizan en el nombre propio de la protagonista: Dora es una adolescente marroquí criada en Francia, de madre holandesa y de padre judío que murió en el campo de 
concentración Dora-Mittelbau; «Mamá me puso ese nombre para que nunca me olvide de dónde vengo» le cuenta a su amiga Lotte, quien le consigue su primer empleo en el archiv del Berlín Document Center. Allí Dora debe inventariar documentos clasificados sobre el periodo nazi y entre ellos encuentra el nombre de su padre, Iakó Bordavid junto a su número de prisionero: 20874. El encuentro con los «Documentos relativos a los judíos de Holanda y sus colonias» representa el comienzo de una reconstrucción identitaria y una búsqueda personal: «Ahora soy una espía. Cuando nadie me ve, saco fotos de los documentos con una Minox usada que compré con mis ahorros», cuenta la protagonista.

En esta primera historia Dora es una adolescente que está descubriendo tímidamente su preferencia sexual por las chicas. Puede intuirse más que asegurarse, que siente una atracción por su amiga Lotte, pero la salida del armario de Dora se hará explícita en la segunda historia. En «Rat line», Odile le pregunta si le gusta Didouche, su amor desde la infancia, a lo que Dora le responde para sorpresa de Odile que cree que no le gustan los hombres [ver figura 5 en anexo] En «El año próximo en Bobigny», la última historia publicada, Dora tendrá su primer encuentro con una chica, Geneviève Junot una actriz de teatro ambulante, con quien comienza una relación. Este proceso de descubrimiento que Dora realiza lentamente se encuentra en relación con lo que Minaverry considera que pudo haberle sucedido a una joven en la década del cincuenta, pero que sin duda puede resonar en el presente. El autor considera que aunque sus historias remiten al pasado, de alguna manera siguen hablando de situaciones de desigualdades vigentes (entrevista personal a I. Minaverry, La Plata, sept. 2011):

[...] la historia se fue convirtiendo en una historia de personajes que representan a alguna minoría, las protagonistas son dos chicas lesbianas: una judía y otra gitana y encima viven en monoblocs... bueno una no, una vive en una camioneta. Digamos que en la época de los nazis tenían todos los números de la rifa para irse a un campo de concentración, todos los triangulitos juntos. Y todos los personajes son de una ex colonia también. Y eso yo lo siento que es como hablar de la gente que vive en las villas o en los monoblocs, los últimos orejones del tarro.

Es necesario señalar que la dimensión feminista y clasista de la historieta es una exploración del autor que asume posiciones políticas que de alguna manera se traducen en su obra. Ante la pregunta sobre la puesta en página de problemáticas que pueden ser leídas desde el feminismo, el autor responde que no se trata de una coincidencia (entrevista personal a I. Minaverry, La Plata, sept. 2011):

Yo soy feminista. Con el feminismo me pasó como con el peronismo, florecieron un montón de cosas en la cabeza. Hay una canción de John Lennon que dice que 
la mujer es el negro del mundo; bueno, me parece que hay conexiones fuertes entre las luchas de las mujeres con las luchas de los trabajadores, los negros, los pueblos de las ex colonias... creo que es eso. Y si yo estoy de acuerdo con que no se discrimine a los negros es lógico que esté de acuerdo con que no se discrimine a las mujeres.

En relación al cuerpo, podemos decir que la puesta en página de chicas comunes como Dora, Odile y Geneviève ha suscitado algunas apreciaciones que dan cuenta de cierta forma disruptiva de concebir a las heroínas, sus acciones y conversaciones. La recepción de la tira en el lectorado inquietaba al autor: «me interesaba saber qué opinión tenían del tema del aborto de Odile [...] Quería saber si lo había tratado bien, porque además no es usual que ese tipo de temas salgan en una historieta, por lo menos en la Fierro o en las historietas argentinas en general» (entrevista personal con el autor, 2011).

En este sentido, la concepción de Griselda Pollock (1988) de «políticas sexuales del mirar» nos permite arriesgar que puede postularse en la historieta un destinatario sexuado como posible lectora: la posición del lector típico de una revista de historietas como Fierro se vería así dislocada produciendo diferentes posiciones dentro de las políticas sexuales del mirar. Afirma Pollock (2010: 278279) que, cuando las mujeres resultan en espectadoras de un texto cuyo destinatario ideal es sexualizado en masculino (universal):

[...] las mujeres ven negada la representación del objeto de su deseo y de su placer y son constantemente borradas, de manera que para mirar y gozar los sitios de la cultura patriarcal, las mujeres tendríamos que convertirnos en travestis nominales. Debemos asumir una posición masculina o gozar en forma masoquista de la humillación de una mujer.

La temática del aborto, postula de entrada un tema que ha sido asignado culturalmente como una preocupación femenina [ver figura 6 en anexo]. El aborto en la clandestinidad es realizado por la partera del barrio, una vecina de la Cité, con una sonda. Es lo único que podemos saber al respecto. El silencio abunda en este capítulo, y solo unas líneas de un rojo furioso dan cuenta de un dolor difícil de poner en palabras y en imágenes. Didouche, el compañero, amigo y amante de Odile, que en otros episodios ha enfrentado golpizas y torturas por ser argelino, inmigrante, pobre, esta vez está ahí pero sin participar, asiste como un autómata sin poder responder a las necesidades de Odile. La identificación que pretendería la tira es, con la posición de Odile, asumir el lugar de la mujer en el discurso, resulta por tanto lo más novedoso y hasta arriesgado del relato [ver figura 7 en anexo].

Además del aborto de Odile la historieta ha incursionado en torno a la representación del cuerpo femenino. La puesta en página de cuerpos que resultan 
disruptivos con el canon de belleza al que suelen adscribir las historietas en el momento de representar el cuerpo femenino se intuyen en elecciones estéticas tales como las pronunciadas caderas de Odile, la representación de chicas de estatura media, con kilitos o pelos en las piernas que contrastan con las representaciones más clásicas que se ha hecho de las mujeres en las historietas [ver figura 8 en anexo]. Dora es un ejemplo de esa búsqueda. En los primeros bocetos el autor la dibujaba altísima y delgada: «un culto a la anorexia» según su propia autocrítica. Finalmente, los personajes por los que optó, menos estilizados obedecen a una decisión ética y estética: «Por más que la historieta no sea tan masiva como la revista Gente o los programas de tele, no quiero colaborar con esa distorsión. Además, no entiendo por qué habría que dibujar a las minas todas iguales, es aburrido e irrespetuoso» afirmó Minaverry en la discusión sobre el cuerpo de Odile a la que podía accederse en su blog. ${ }^{7}$

\section{Reflexiones finales}

Tres recorridos espaciales han trazado este ensayo:

El primero, en referencia al lenguaje de la historieta y su representación secuencial en el espacio. La historieta puede ser entendida como un relato híbrido que combina trazos (dibujos) y signos (letra) en forma de una zona inbetween que puede ser entendida como un tercer espacio. Tal como Teresa de Lauretis sostiene, este tercer espacio «es un movimiento entre lo representado y lo que la representación deja fuera o, más directamente, hace irrepresentable [...]. Estos dos espacios no están ni en oposición uno con otro ni ensartados en una cadena de significados sino que existen simultáneamente y en contradicción» (citada en Soja, 2010).

En segundo término, las geografías imaginarias que recrea Minaverry recorridas por una heroína atípica. El autor construye una tríada socio espacio temporal -fines de los cincuenta y comienzos de los sesenta en Europa y Sudamérica- en la que se imbrican relaciones de género, generacionales, geoculturales, entre otras, puestas en página a partir de mapas, fotos de archivo y una cuidadosa aproximación a eventos históricos. Los procesos de desnazificación en la Berlín de la posguerra, las formas de resistencia de los migrantes de las ex colonias en la Francia de comienzos de los sesenta y la Argentina de la proscripción peronista

7. En el blog del autor www.minaverry.wordpress.com podía accederse al proceso de producción y a discusiones que Minaverry tenía con su lectorado en torno a tópicos que enriquecieron este trabajo; lamentablemente, en la actualidad, el blog permanece con acceso restringido (consultado 10 de abril 2012). 
se reinscriben en el presente desde una «política del mirar» que implica marcas de clase, etnia y géneros que resultan disruptivas.

Finalmente, el cuerpo y la sexualidad de las mujeres dibujadas se ve trastocado. Ellas han solido ser las encargadas de encarnar diversas fantasías o miedos masculinos: villanas hermosas e hipersexualizadas, heroínas que resultan ser versiones devaluadas de un prototipo masculino y compañeras -novias eternascaídas en desgracia, útiles para que los héroes lucieran sus habilidades. Las que no se ajustaban al canon de belleza eran las matronas, gordas y ridiculizadas, siempre con un palo de amasar en la mano. Pero el esquematismo entre la mujer fatal o la fatal mujer se ve conmovido con la historia de Dora. Las chicas Minaverry comenzaron por hablar de «cosas de mujeres»: política, cambio social, pasado reciente, y por supuesto, sexualidad, amor, deseo. No parece casual que la posición desde la que se asume el autor, sea clasista y feminista: temáticas ausentes en las historietas de espías clásicas como aborto, sexualidad disidente, heteronorma y luchas que producen ecos en la memoria colectiva como la resistencia peronista en la Argentina o los derechos de las minorías que no refieren solo al pasado sino que apuntan de manera inquietante a nuestro presente actual. Tampoco parece ser un detalle menor el interés manifiesto de Minaverry por la espacialidad como generadora de subjetividades de resistencia, como puede desprenderse de proyectos paralelos que lo tienen como protagonista, como el mencionado blog La Teja.

El hecho de que es posible afirmar de que la historieta propone una lectora femenina, o al menos temáticas que han sido sancionadas como «de mujeres» en una revista que básicamente se dirige a un lector masculino, produce una disrupción inquietante: una especie de margen desde el que mira el autor, entre Europa y Sudamérica, entre el pasado y el presente, entre lo masculino y lo femenino. Un entre-espacios que puede ser entendido como Gloria Anzaldúa en su conciencia de la mestiza: «Soy un amasijo, que une y junta, y que no solo ha dado lugar a un producto de la oscuridad y a un producto de la luz, sino también a un producto que cuestiona las definiciones de luz y oscuridad y les da nuevos significados»» (citada en Soja, 2010: 202-203). 
Anexo

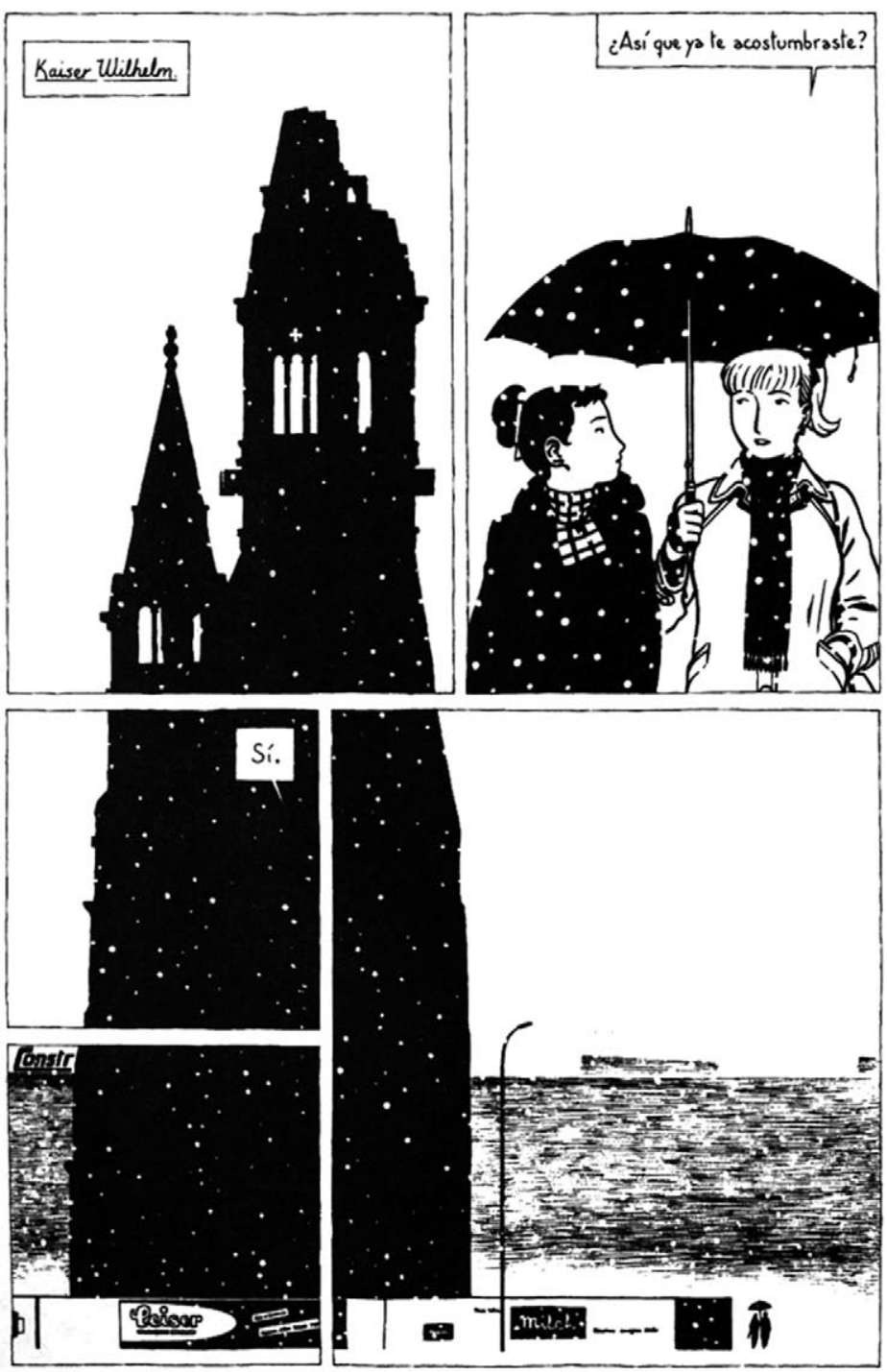

Figura 1

«20874», capítulo 4, Fierro, 16, p. 36 

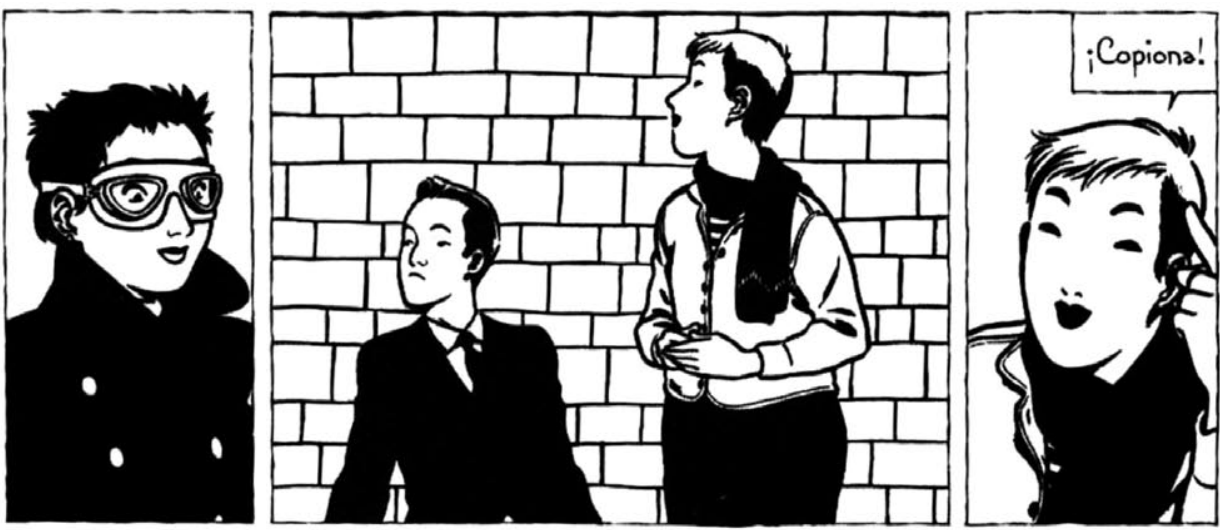

"Clento doce jud1os fueron seleccionados oon el propbsito de completar la ooleccion de esqueletos de la Re1chsuniversität de Bstrasburgo. Se tomaron sus fotograflas $\mathrm{y}$ sus medidas antropologicas, y se $108 \mathrm{ases}$ inó. Luego se h1cieron estudios comparativos; Investigac1on anatómica; estud10s de raza, rasgos patologicos del cuerpo, forma $y$ tamano del cerebro; entre otros. Los cuerpos fueron enviados a Estrasburgo y descarnados."

Figura 2

«Rat line», capítulo 3, Fierro, 25, p. 60

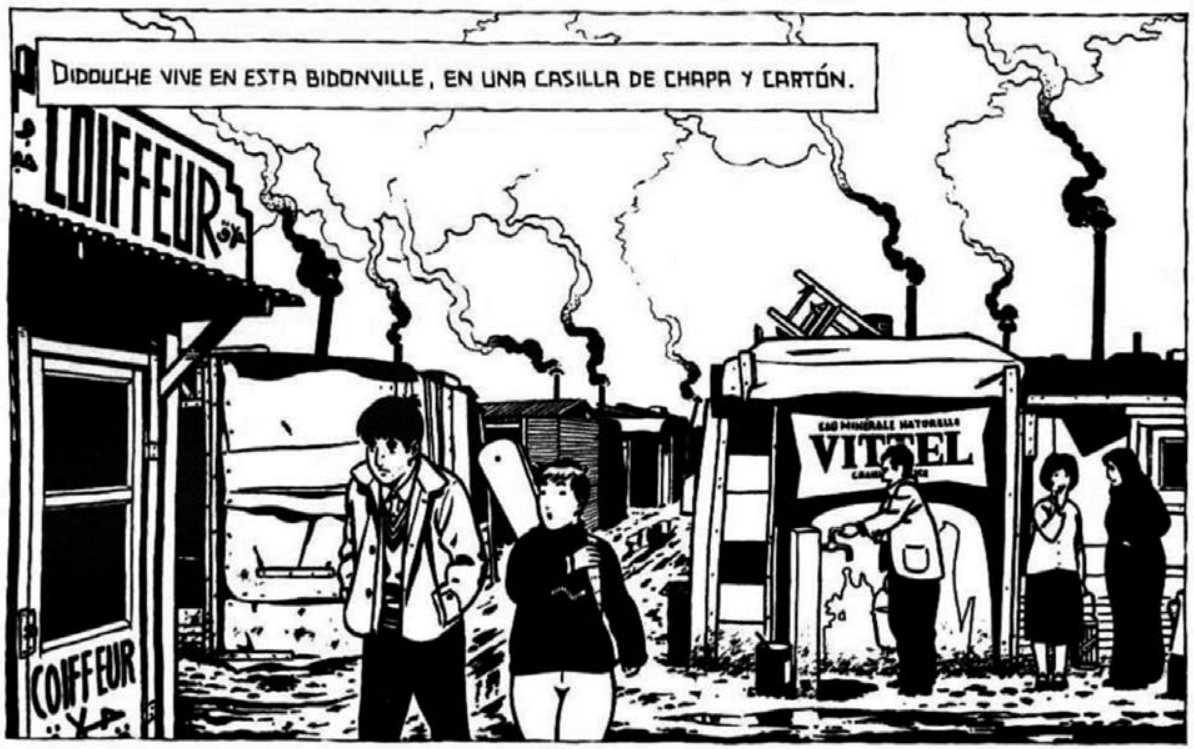

Figura 3

Bidonville en «El año próximo en Bobigny», cap .1, Fierro, 41, p. 59 


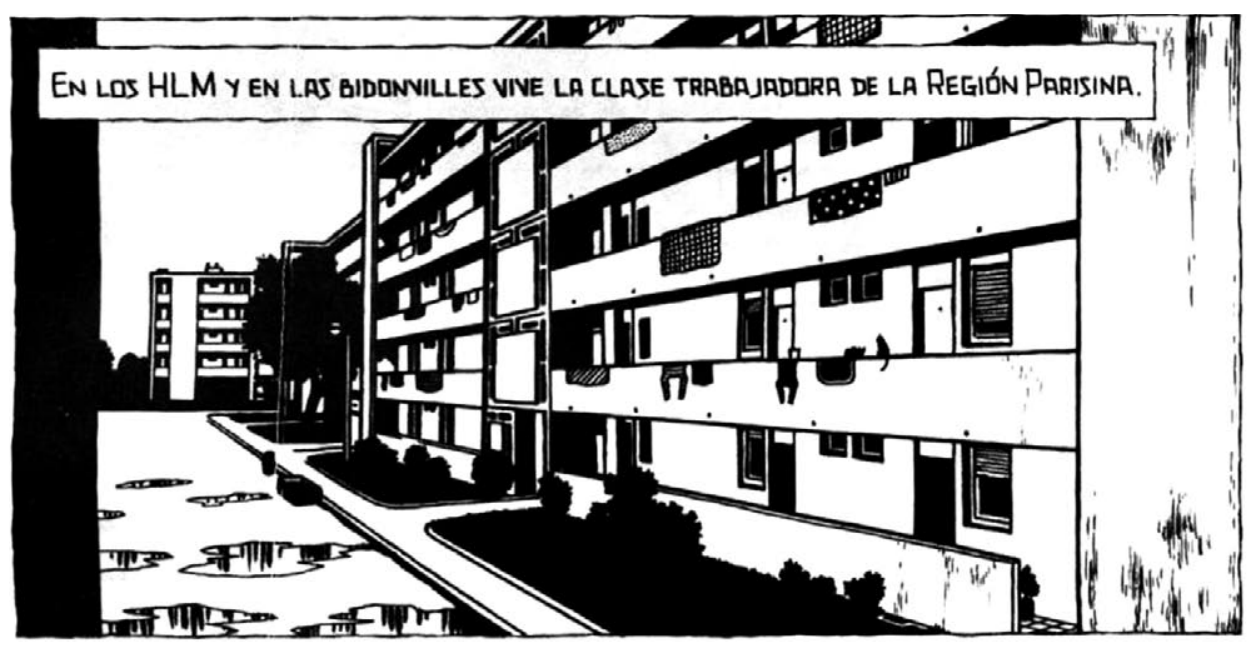

Figura 4

HLM en «El año próximo en Bobigny», cap. 1, Fierro, 41, p. 62
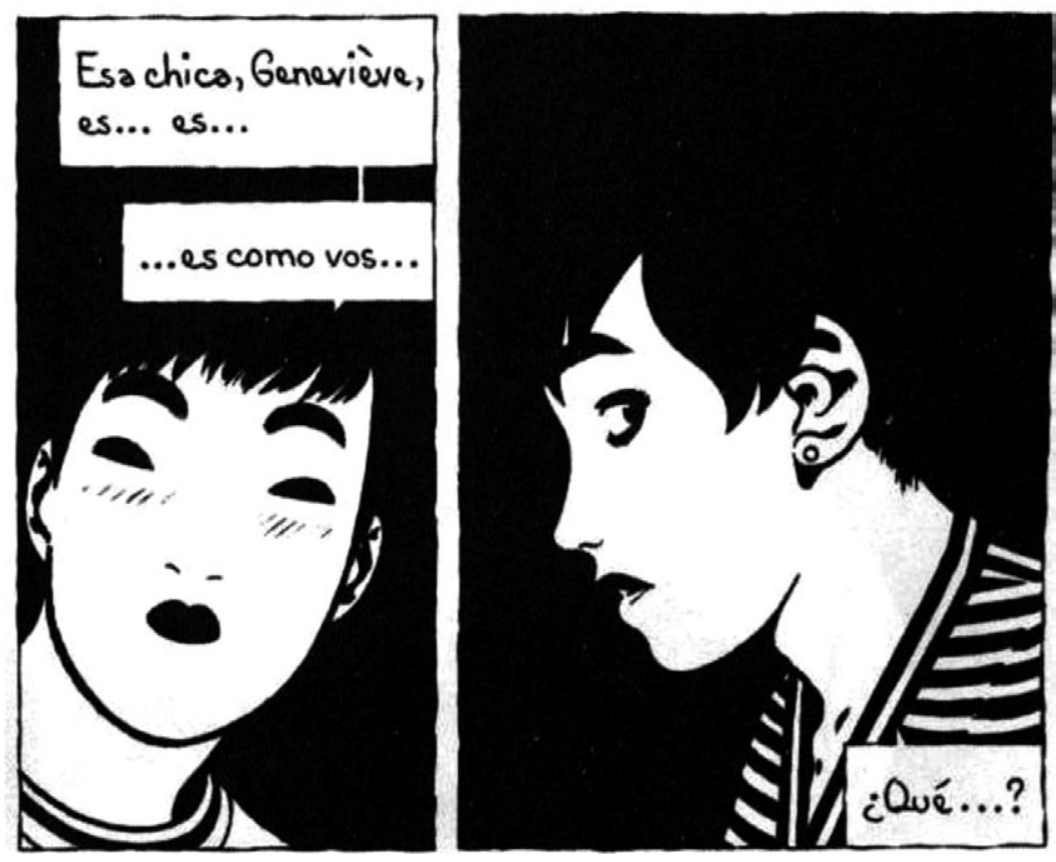

Figura 5

«El año próximo en Bobigny», cap. 4, Fierro, 45, p. 59 

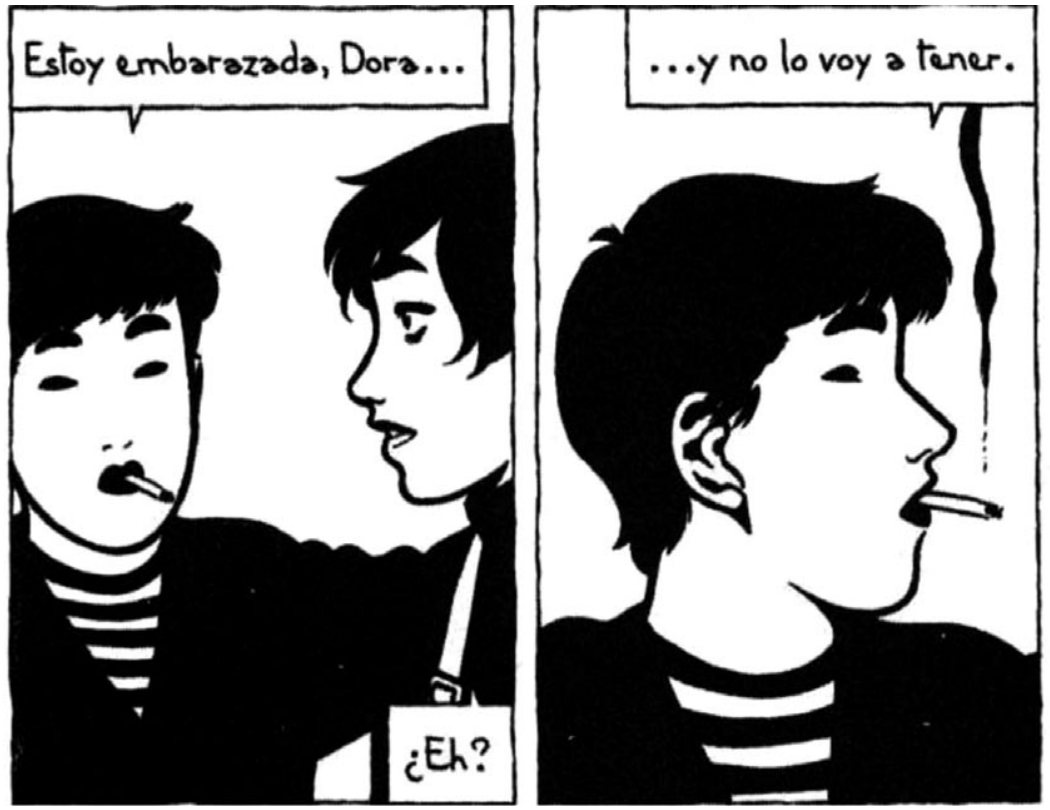

Figura 6

«El año próximo en Bobigny», cap. 8, Fierro, 50, p. 74
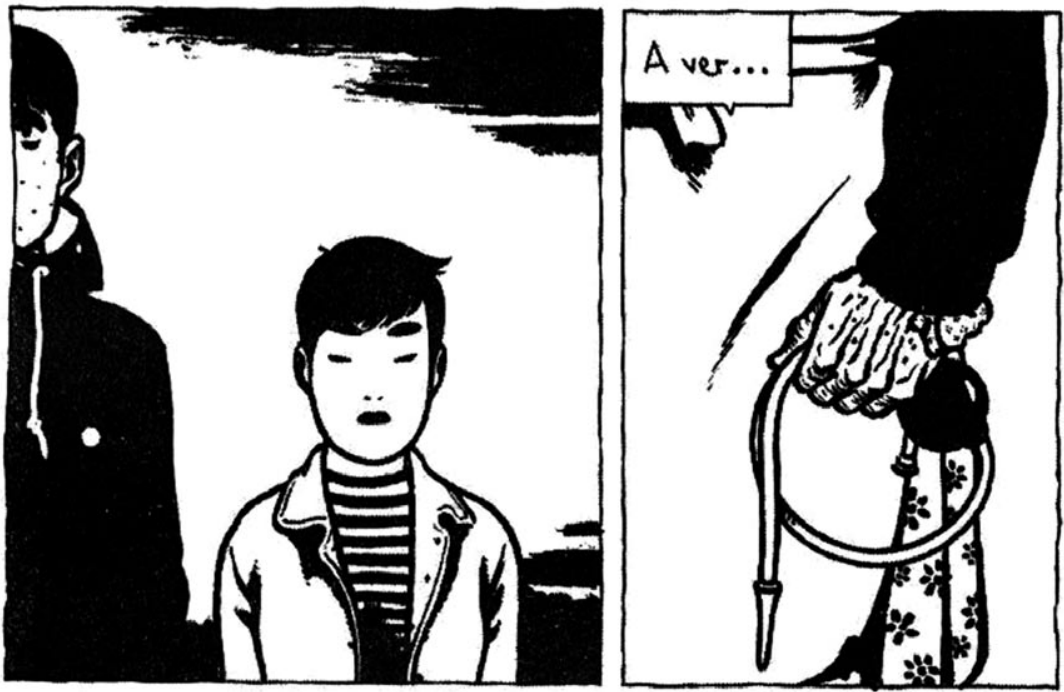

Figura 7

«El año próximo en Bobigny», cap. 12, Fierro, 57, pp. 69-70 


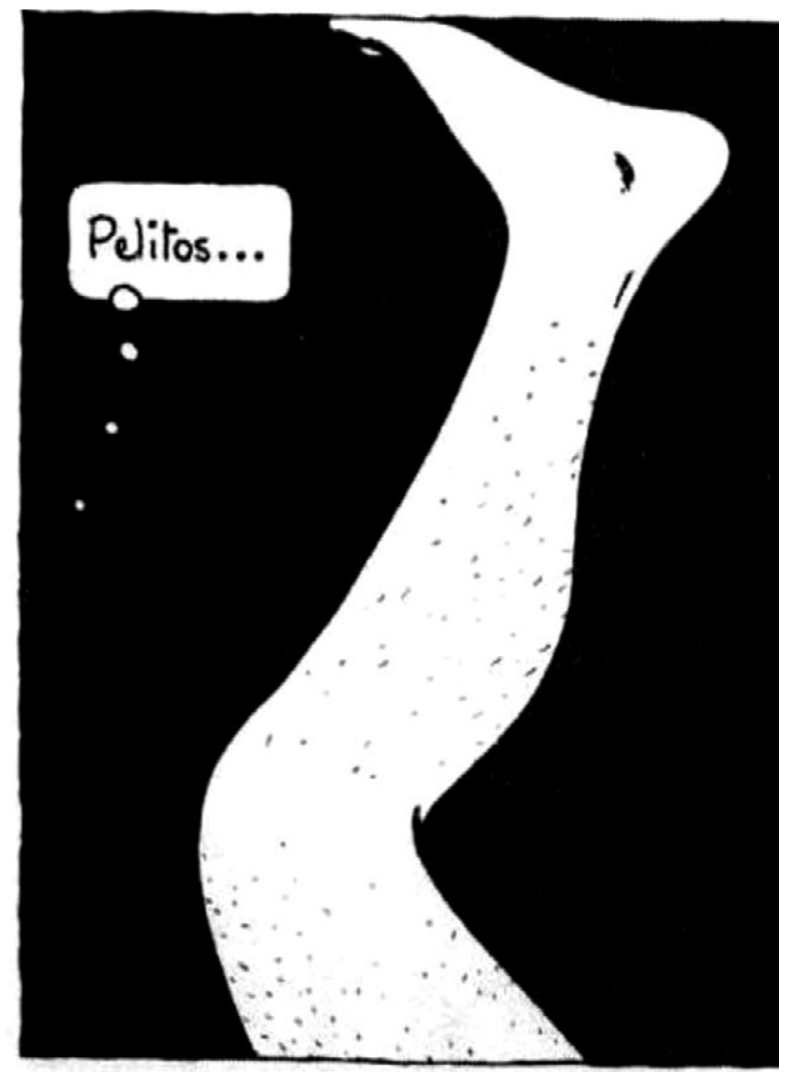

Figura 8

«El año próximo en Bobigny», cap. 4, Fierro, 45, p. 60

Aunque las viñetas 1 y 2 tienen el mismo tamaño, podemos apreciar que tienen un efecto de sentido diferente en la narración. La viñeta 1 conforma un cuadro más amplio con las viñetas 3, 4 y 5, que componen la imagen de la Iglesia Memorial Kaiser Wilhelm. La viñeta 2 es una especie de plano detalle de la viñeta 5 en el que las diminutas siluetas del último cuadro resaltan la dimensión del tamaño del edificio.

Mientras el lenguaje verbal relata los horrores de los experimentos nazis, el lenguaje icónico muestra a Dora viajando en moto por Francia hacia el encuentro con sus nuevos amigos de Bobigny en el puente. El comentario de Odile, cuando ve a Dora, «copiona», en referencia a su corte de pelo, no se encuentra en relación con la narración en off; sin embargo, la escena es perfectamente entendible y construye la cotidianidad de convivir con un pasado que no se ha agotado en el presente de la protagonista, aunque esté en otro país y en otra época. 


\section{Referencias bibliográficas}

Foucault, M. (s/f): «Utopías y heterotopías» y «El cuerpo utópico» disponibles en http://www.mxfractal.org/RevistaFracta148MichelFoucault.html

Massey, D. (1998): «Espacio, lugar y género», Debate Feminista, ISIS Internacional, vol. 17, año 9, México, DF.

Nogué I Font, J. (1989): «Espacio, lugar, región. Hacia una nueva perspectiva geográfica regional», Boletín de la Asociación de Geógrafos Españoles, 9: 63-79.

Oyón Bañales, J. L. (2002): «Historia urbana e historia obrera: reflexiones sobre la vida obrera y su inscripción en el espacio urbano 1900-1950», Historia Contemporánea, 24: 11-58.

Pollock, G. ([1988] 2007): «Modernidad y espacios de la feminidad», en Cordero Reiman, K.; I. Sáez (comp.): Crítica feminista en la teoría e historia del arte, México, Universidad Iberoamericana, 249-281.

Reggiani, F. (2008): «Ni literatura ni cine: Puesta en página y enunciación en historieta (a partir de algunas lecturas de Fernando Felipe)», en AA.vV. (eds.), Siglos XX y XXI. Memoria del Primer Congreso internacional de Literatura y Cultura Españolas Contemporáneas http://www.memoria. fahce.unlp.edu.ar/trab_eventos/ev.353/ev.353.pdf consultado 3/01/12.

- (2009): "Análisis, síntesis y velocidad: la construcción de la secuencia en historieta como lugar de emergencia de la instancia de enunciación», Diálogos de la Comunicación, 78: 1-11.

- (2010): «¿Quién 'dice’ una historieta?: Historietas y teoría de la enunciación, un resumen» en AA.vv. (eds.); Primer Congreso internacional de Historietas «Viñetas Serias». http://www.vinetas-sueltas.com.ar/congreso/ pdf/HistorietaLenguajeyRepresentacion/reggiani.pdf consultado 3/01/12.

- (2011): «Del texto a la imagen: Lugares de la verdad en la historieta. Una lectura de Alack Sinner, de José Muñoz y Carlos Sampayo», Estudios y crítica de la historieta argentina, 44: 1-16.

Rose, G. (1999): «Performing Spaces», en Allen, J.; D. Massey; P. Sarre (eds.): Human geography today, Cambridge, UK, Polity Press.

SierRa, M. (2010): "Of “Other Spaces": Norah Borges' Gendered Visions» (Manuscrito inédito).

SoJA, E. ([1999] 2010): «Tercer Espacio: extendiendo el alcance de la imaginación geográfica», en Benach, N.; A. Albet (eds.), Edward Soja: La perspectiva postmoderna de un geógrafo radical, Barcelona, Icaria, 181-209.

Steimberg, O. (2005): «Proposiciones sobre el género», en STeimberg, O. Semiótica de los medios masivos. El pasaje a los medios de los géneros populares, Buenos Aires, Atuel, 39-84 
TorRes, F. (2005): «Los barrios 'sensibles' y la revuelta urbana francesa», Página Abierta, 165, diciembre de 2005. Disponible en: http://www.pensamientocritico.org/frator1205.htm 